\title{
Improvement of Statistical Typhoon Rainfall Forecasting with ANN-Based Southwest Monsoon Enhancement
}

\author{
Tsung-Yi Pan ${ }^{1}$, Yi-Ting Yang ${ }^{2}$, Hung-Chi Kuo ${ }^{1,2,6,{ }^{*}}$, Yih-Chi Tan ${ }^{1,3,4}$, Jihn-Sung Lai ${ }^{1,3,4}$, \\ Tsang-Jung Chang ${ }^{1,3,5}$, Cheng-Shang Lee ${ }^{2}$, and Kathryn Hua Hsu ${ }^{1}$ \\ ${ }^{1}$ Center for Weather Climate and Disaster Research, National Taiwan University, Taipei, Taiwan, ROC \\ ${ }^{2}$ Department of Atmospheric Sciences, National Taiwan University, Taipei, Taiwan, ROC \\ ${ }^{3}$ Department of Bioenvironmental System Engineering, National Taiwan University, Taipei, Taiwan, ROC \\ ${ }^{4}$ Hydrotech Research Institute, National Taiwan University, Taipei, Taiwan, ROC \\ ${ }^{5}$ Ecological Engineering Research Center, National Taiwan University, Taipei, Taiwan, ROC \\ ${ }^{6}$ Taida Institute of Mathematical Sciences, National Taiwan University, Taipei, Taiwan, ROC
}

Received 28 February 2011, accepted 4 July 2011

\begin{abstract}
Typhoon Morakot 2009, with significant southwest monsoon flow, produced a record-breaking rainfall of $2361 \mathrm{~mm}$ in 48 hours. This study hopes to improve a statistical typhoon rainfall forecasting method used over the mountain region of Taiwan via an artificial neural network based southwest monsoon enhancement (ANNSME) model. Rainfall data collected at two mountain weather stations, ALiShan and YuShan, are analyzed to establish the relation to the southwest monsoon moisture flux which is calculated at a designated sea area southwest of Taiwan. The results show that the moisture flux, with southwest monsoon flow, transported water vapor during the landfall periods of Typhoons Mindulle, Bilis, Fungwong, Kalmaegi, Haitaing and Morakot. Based on the moisture flux, a linear regression is used to identify an effective value of moisture flux as the threshold flux which can enhance mountain rainfall in southwestern Taiwan. In particular, a feedforward neural network (FNN) is applied to estimate the residuals from the linear model to the differences between simulated rainfalls by a typhoon rainfall climatology model (TRCM) and observations. Consequently, the ANNSME model integrates the effective moisture flux, linear rainfall model and the FNN for residuals. Even with very limited training cases, our results indicate that the ANNSME model is robust and suitable for improvement of TRCM rainfall prediction. The improved prediction of the total rainfall and of the multiple rainfall peaks is important for emergency operation.
\end{abstract}

Key words: Southwest monsoon, Statistical typhoon rainfall forecasting, Artificial neural networks, Moisture flux

Citation: Pan, T. Y., Y. T. Yang, H. C. Kuo, Y. C. Tan, J. S. Lai, T. J. Chang, C. S. Lee, and K. H. Hsu, 2011: Improvement of statistical typhoon rainfall forecasting with ANN-based southwest monsoon enhancement. Terr. Atmos. Ocean. Sci., 22, 633-645, doi: 10.3319/TAO.2011.07.04.01(TM)

\section{INTRODUCTION}

Taiwan is located in the hot zone of the Western Pacific typhoon tracks with an average three to five typhoons making landfall in Taiwan each year. While the typhoon rainfall is the most important water resource in Taiwan, it also causes serious disasters. Obviously, the typhoon rainfall prediction affects disaster mitigation and emergency operations. The importance of the central mountain range in typhoon precipitation has long been realized (e.g., Hong et al. 2010; Lin et al. 2010). The long term rainfall data suggest

\footnotetext{
* Corresponding author

E-mail:kuo@as.ntu.edu.tw
}

that the mountain stations of ALiShan and YuShan often experience extreme typhoon rainfall. The interactions of summer or winter monsoons as important factors that contribute to the extreme rainfall in Taiwan are also recognized by the meteorological community (e.g., Wu et al. 2009; Chien and Kuo 2011; among many others).

Typhoon Morakot 2009 produced a record-breaking rainfall, $2361 \mathrm{~mm}$ in 48 hours, causing the most serious flood and landslide disaster in southwestern Taiwan in 50 years. Typhoon Morakot's landing on Taiwan occurred concurrently with the cyclonic phase of the intra-seasonal oscillation, which may have enhanced the background southwesterly flow. The extreme rainfall event is caused by the 
continuous formation of mesoscale convection with the water vapor supply from the southwest (SW) monsoon surge, and the very slow movement of Typhoon Morakot both in the landfall and in the post landfall periods. The Typhoon Morakot case thus suggests the importance of multiple scale processes interaction on producing the extreme rainfall. In particular, the importance of the SW monsoon flow providing the water vapor for heavy rain is emphasized in Ge et al. (2010), Hong et al. (2010), and Chien and Kuo (2011). Another example of SW monsoon flow interaction with a typhoon is the case of Typhoon Mindulle (2004), which also caused severe flooding over central and southwestern Taiwan (Chien et al. 2008; Lee et al. 2008).

The quantitative typhoon rainfall forecast in Taiwan is often used with a statistical approach based on the relation between the observed rainfall pattern and the tracks of typhoon in the climatology model (e.g., Lee et al. 2006, the Typhoon Rainfall Climatology Model, TRCM). The statistical method uses the fact that precipitation is often phase locked with the central mountain range, thus knowing the track of a typhoon allows the prediction of a precipitation pattern and the quantity of the rain from the typhoon climatology history. For typical typhoons, a forecast model such as the TRCM often gives very reasonable rainfall estimate on the $100 \mathrm{~km}$ scale for the $24-36$ hour time scale. For extreme rainfall event such as Typhoon Morakot, factors such as the water vapor supply by a SW monsoon flow may not be well represented in the TRCM, as most of the typhoons do not necessarily converge with a strong SW monsoon flow.

Due to the complex interaction between a typhoon and seasonal monsoon, we use an artificial neural network (ANN) algorithm to improve the statistical forecast model such as TRCM to examine the effect of a SW monsoon on extreme mountain rainfall. The ANN algorithm is an attractive inductive approach in rainfall prediction because of their highly nonlinearity, flexibility and data-driven learning in building models without any prior assumptions concerning the data distribution (Gardner and Dorling 1998). For rainfall forecasting, French et al. (1992) designed a Multi-InputMulti-Output (MIMO) Back-Propagation Neural Network (BPNN) to perform one-hour-ahead rainfall forecasting for two dimensional fields associated with observed rainfall. Furthermore, remote sensing data were used to estimate the rainfall through the ANN algorithms, which served the purpose of both data classification and approximation (Hsu et al. 1997; Bellerby et al. 2000; Hong et al. 2004; Chen et al. 2008). Olsson et al. (2004) applied wind speed and humidity data reproduced by atmospheric numerical modeling to generate regional rainfall using an ANN approach. For typhoon rainfall forecasting, Lin and Chen (2005) and Lin et al. (2009) used typhoon characteristics such as maximum wind, central pressure, location and the radius of $15 \mathrm{~m} \mathrm{~s}^{-1}$ wind as BPNN's inputs to forecast one-hour-ahead typhoon rainfall. In this study, we improve the TRCM rainfall prediction with the SW monsoon enhancement based on the ANN algorithm. The ANN algorithm and the data are described in section 2. The results are in section 3 and conclusion in section 4 .

\section{DATA AND METHOD}

Due to the lifting of typhoon flow over the Central Mountain Range (CMR), Wang (1992) and Chang et al. (1993) concluded that the hourly rainfall distributions over the Taiwan area is displayed as a function of the typhooncenter location. Lee et al. (2006) developed the TRCM to forecast typhoon rainfall. The model domain is confined within $19-27^{\circ} \mathrm{N}, 118-126^{\circ} \mathrm{E}$, with 256 grid boxes $\left(0.5^{\circ} \times\right.$ $0.5^{\circ}$ latitude-longitude grid box). The hourly rainfall data of total 371 rain gauges from 1989 - 2007 are used in the statistics. During the typhoon event, the hourly rainfall at each rain gauge could be forecasted through the TRCM based on the typhoon track prediction issued by the Central Weather Bureau (CWB). The ALiShan and YuShan weather stations are used in the present study (Table 1).

Six hourly (at 0000, 0600, 1200, and 1800 UTC) gridded operational analyses from the European Centre for Medium-Range Weather Forecasts - Tropical Ocean Global Atmosphere (ECMWF - TOGA) were used to estimate the moisture flux at $925 \mathrm{hPa}$ for our ANN algorithm. The dataset is with $1.125^{\circ} \times 1.125^{\circ}$ resolution and the domain is from 110.25 to $120.375^{\circ} \mathrm{E}$ and from 16.875 to $22.5^{\circ} \mathrm{N}$ (Fig. 1)

Table 1. The profile of ALiShan and YuShan weather stations

\begin{tabular}{ccccc}
\hline \multirow{2}{*}{ Official ID } & \multirow{2}{*}{ Name } & \multicolumn{3}{c}{ Position } \\
\cline { 3 - 5 } & & Longitude & Latitude & Altitude (m) \\
\hline \multirow{2}{*}{46753} & ALiShan & 120.81 & 23.51 & 2413.4 \\
46755 & YuShan & 120.95 & 23.49 & 3844.8 \\
\hline \multirow{2}{*}{ Official ID } & \multirow{2}{*}{ Name } & Obs. Frequency & Watershed & Set up (year) \\
\cline { 3 - 5 } 46753 & ALiShan & 8 & Zengwun River & 1933 \\
46755 & YuShan & 8 & Gaoping River & 1943 \\
\hline
\end{tabular}



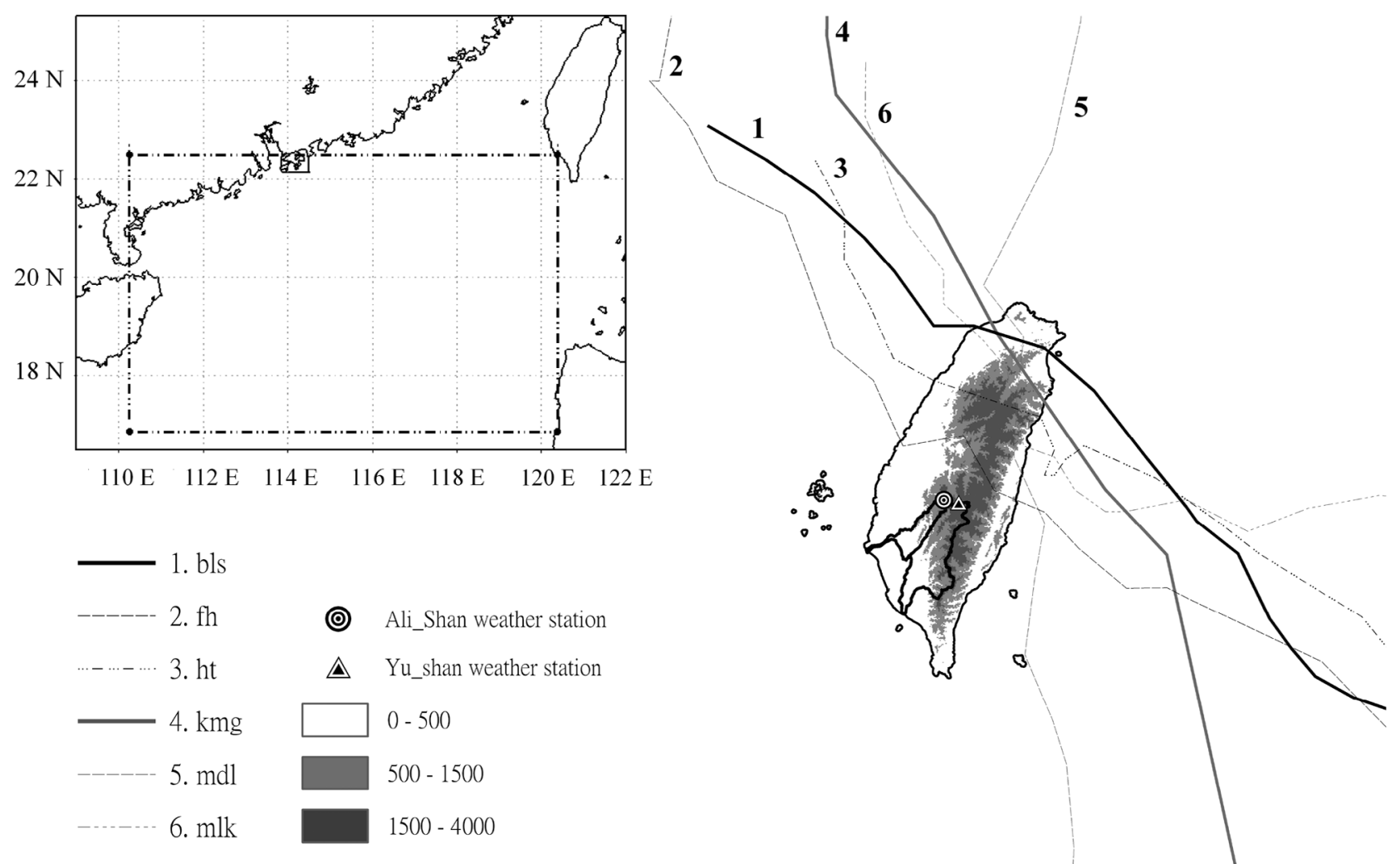

Fig. 1. The topography of Taiwan with locations of weather stations, watersheds and the domain for detecting the strength of the SW monsoon, and the tracks of the six selected typhoons.

which consisted of 60 grid points. Figure 1 also shows the locations of the 22 weather stations which provide long-term precipitation observations. The moisture flux is defined by $\left(\sqrt{u^{2}+v^{2}}\right) q$, where $q$ is the specific humidity, $u$ and $v$ are zonal and meridional velocity $\left(\mathrm{m} \mathrm{s}^{-1}\right)$, respectively. We calculate the average moisture flux $Q$,

$Q=\frac{\sum_{1}^{60}\left(\sqrt{u^{2}+v^{2}}\right) q}{60}$

with the SW monsoon in mind, the flux is estimated only when $u \geq 0$ and $v \geq 0$.

Tsoi and Back (1997) classified ANNs into two categories, feedforward neural networks (FNNs) and recurrent neural networks (RNNs). Although Pan et al. (2007) showed that RNNs perform superiorly for dynamical systems, FNNs is still one of the most popular forms due to its ability of simplifying calculation and enhancing the adaptability. Based on the learning algorithms of ANNs, unsupervised ANNs are applied in classification or clustering while supervised ANNs are adopted as a function approximator. In this study, a supervised FNN is designed for approximating the residual rainfalls of moisture flux- rainfall intensity regression as shown in Fig. 2.

Figure 2 also shows four essential elements to compose a FNN: neurons, activation functions, layers and connections. A neuron, like a standalone unit, performs static mapping between the input and output through a linear or nonlinear activation function. The activation function adopted for the hidden layer is a hyperbolic tangent sigmoid transfer function as following Eq. (2).

$f_{h}=\frac{2}{1+\exp (-2 \cdot n e t)}-1$

where the $f_{h}$ is the response of the neuron $h$ excited by net. The connections among neurons determine the dynamics of a network, like data flow. Because ANNs are trained by data-driven learning algorithms, and the data-driven learning algorithms always develop full connections between neurons in different layers (Pan et al. 2007), the dynamics of a network could be accounted as the strengths of connections, like the weights in Fig 2. Therefore, the input net of a neuron in the hidden and output layers are described as Eqs. (3) and (4), respectively.

$n e t_{h}=\sum_{i=1}^{m} w_{i, h}^{H} \cdot u_{k, i}+w_{h}^{b^{H}} \cdot b^{H}$

$n e t_{O}=\sum_{i=1}^{h} w_{i, n}^{o} \cdot f_{i}+w_{n}^{b^{o}} \cdot b^{o}$ 


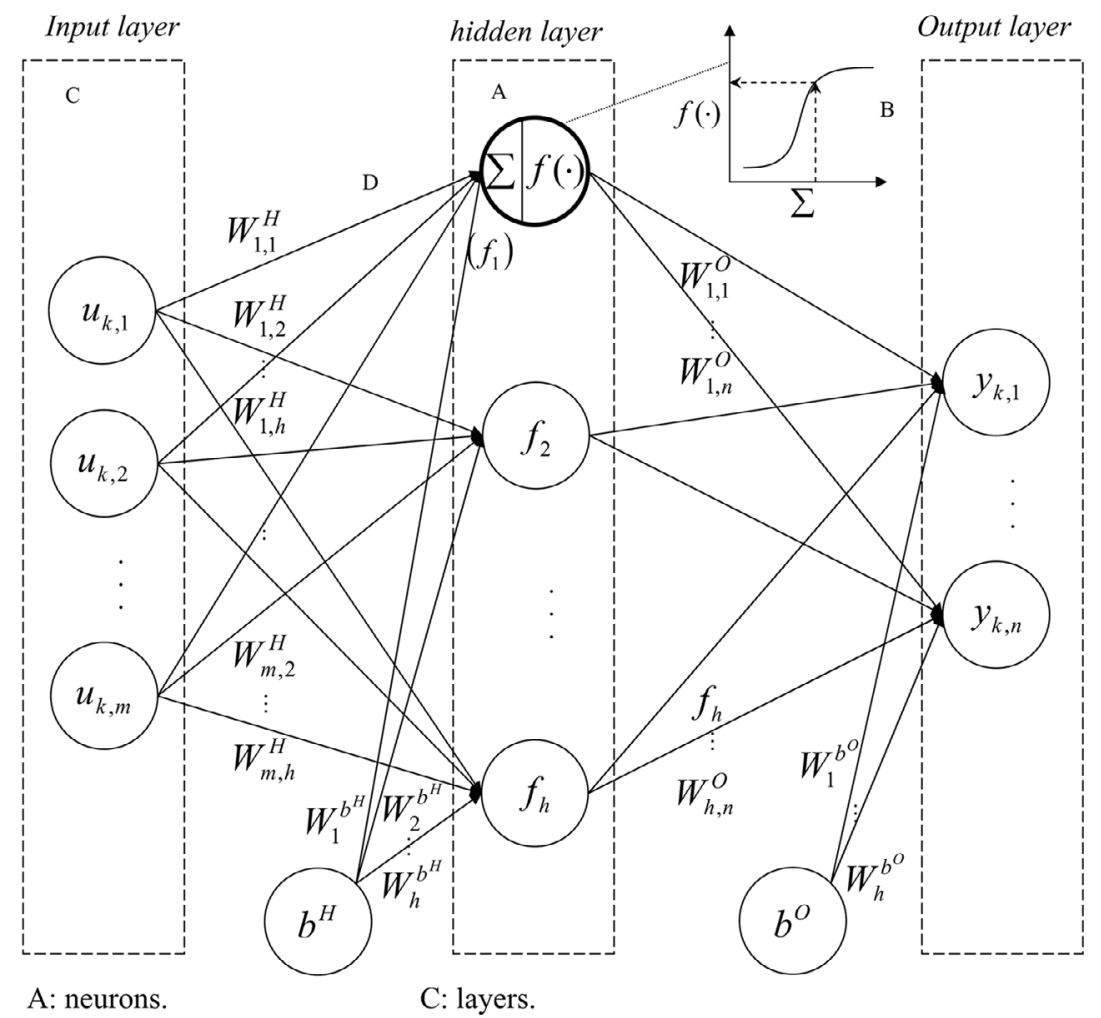

Fig. 2. A feedforward neural nework (FNN) with 1-hidden-layer multiple-input-multiple-output (MIMO) framework.

where $w_{i, h}^{H}$ and $w_{i, n}^{O}$ mean the weight of the signal $u_{k, i}$ from the $i^{\text {th }}$ input neuron to the $h^{\text {th }}$ hidden layer neuron and the weight of the signal $f_{i}$ from the $i^{\text {th }}$ hidden layer neuron to the $n^{\text {th }}$ output neuron, respectively, and $w_{h}^{b^{u}}$ and $w_{n}^{b^{\circ}}$ present the weight of bias $b^{H}$ in the hidden layer and the weight of bias $b^{O}$ in the output layer, respectively. For determining all weights mentioned above, a conjugate gradient backpropagation with Fletcher-Reeves updates (Scales 1985) is adopted to train the supervised ANN. A layer is composed by a collection of neurons arranged conveniently in a onedimensional array. In general, a FNN includes an input layer, an output layer, and hidden layers. The greater the number of hidden layers embedded in a FNN, the greater the complexity of the model. However, one hidden layer is used in most of the applications due to its simplicity. By composing the four elements, an arrangement of neurons interconnected by connections in space forms the architecture of an FNN. Based on the architecture of an FNN, the input layer takes the input signals and delivers them to every neuron in the next layer, the hidden layer, which represents the features that relate the outputs of the neural network to the inputs. The output layer takes the hidden layer signals and adds them to each output neuron as the outputs of the FNN. The output of FNN is used to improve the prediction.

Figure 3 is the flowchart of our work. With the selected typhoon cases and the area of SW monsoon moisture flux, the hourly rainfall intensities derived from the TRCM based on the typhoon tracks are compared with the observed hourly rainfall intensities of the CWB and evaluated the difference, denoted as DIFF in Fig. 3. The moisture flux of the area SW of Taiwan is calculated from the ECMWF-TOGA data. We found that the peak precipitation is not necessary to follow the occurrence of the peak of SW moisture flux. It is likely that the mesoscale convection is important and the peak rainfall resulted when sufficient moisture supply exists. A threshold of effective moisture flux contributing to the extra rainfall in the specified weather station is identified based on a transition point detecting method. The relation between the effective moisture flux and the extra rainfall $(D I F F)$ is evaluated by a preliminary linear regression and a FNN for residual estimation that integrated as the ANNSME.

The interaction of SW monsoon and typhoon circulation with the terrain often causes significant rainfall in the southwestern Taiwan, especially the upstream watersheds of the Gaoping River and the Zengwun River (Fig. 1). Our data base is comprised of landfall typhoons from 2000 to 2009 with cumulative rainfall over $400 \mathrm{~mm}$ per event in each of the mountain station, and also with northeast-southwest rain bands. The selected typhoons are Mindulle in 2004, Haitang in 2005, Bilis in 2006, Fungwong in 2008, and Morakot in 2009. Moreover, Typhoon Kalmaegi 2008, with mountain rainfall less than $400 \mathrm{~mm}$, is added to the data base due to 
its extreme rainfall over the plain and the significant SW monsoon (Tsai et al. 2010). The six selected typhoons are all with southeastern-northwestern oriented track, which will produce rainfall in SW of Taiwan over the mountain region.
Table 2 summarizes the profiles of the typhoons and the precipitations for the ALiShan and YuShan weather stations. The period $\mathrm{A}$ is from the CWB sea warning time to two days after the end of the sea warning, and the period $\mathrm{B}$ is only the post-landfall time. Note that the rainfall is

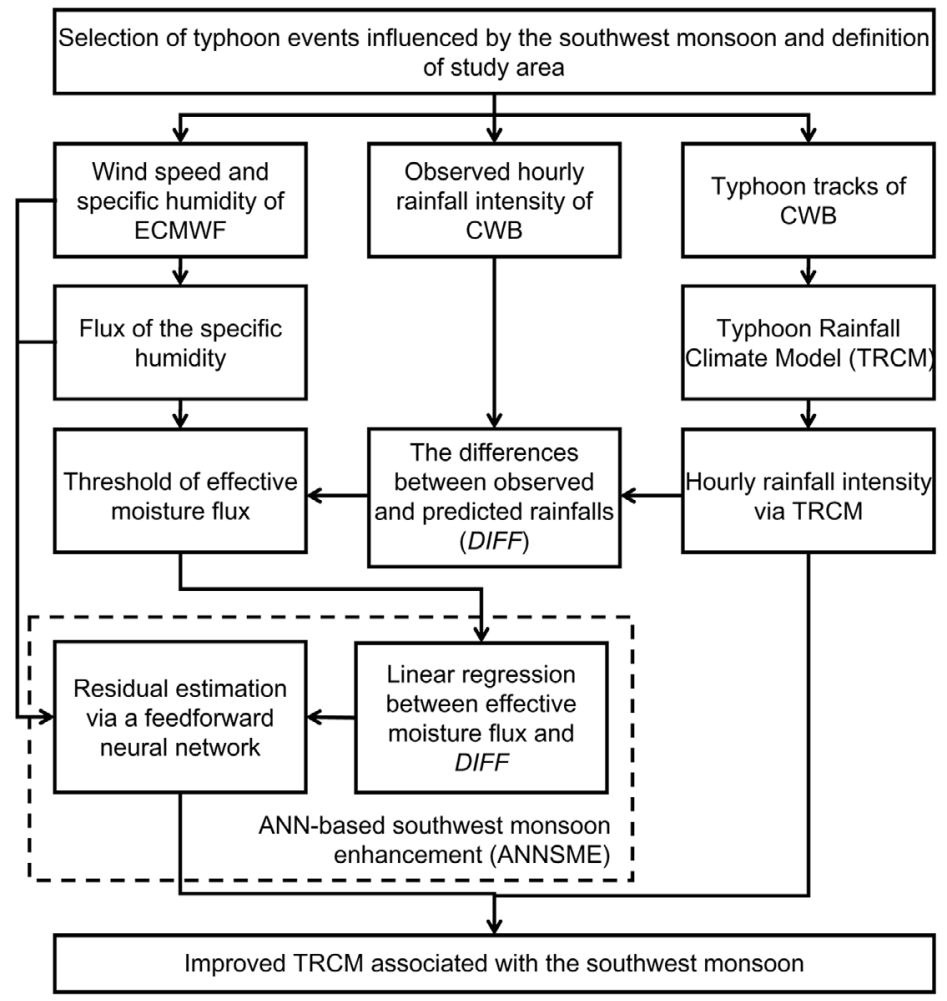

Fig. 3. Flowchart of the improved TRCM rainfall prediction with SW monsoon.

Table 2. The profile of the selected typhoon events.

\begin{tabular}{|c|c|c|c|c|c|c|c|c|}
\hline \multirow{2}{*}{ Year } & \multirow{2}{*}{ Typhoon } & \multicolumn{3}{|c|}{ Central pressure (mb) } & \multirow{2}{*}{ Categ. } & \multicolumn{3}{|c|}{ Time (local time: $\mathbf{m m} / \mathrm{dd}$ hh) } \\
\hline & & Minimum & Landfall & Leave land & & Landfall & Leave land & Analyzed time \\
\hline 2004 & Mindulle & 916 & 975 & 983 & 2 & $07 / 0122$ & $07 / 0210$ & $06 / 28-07 / 05$ \\
\hline 2005 & Haitang & 898 & 925 & 955 & 3 & $07 / 1814$ & $07 / 1822$ & $07 / 16-07 / 22$ \\
\hline 2006 & Bilis & 987 & 978 & 978 & TS & $07 / 1322$ & $07 / 1401$ & $07 / 12-07 / 17$ \\
\hline 2008 & Kalmaegi & 956 & 970 & 990 & 1 & $07 / 1721$ & $07 / 1807$ & $07 / 16-07 / 20$ \\
\hline 2008 & Fungwong & 952 & 948 & 970 & 2 & 07/28 06 & $07 / 2814$ & $07 / 26-07 / 31$ \\
\hline 2009 & Morakot & 954 & 955 & 975 & 1 & $08 / 0723$ & 08/08 14 & $08 / 05-08 / 12$ \\
\hline \multirow{2}{*}{ Year } & \multirow{2}{*}{ Typhoon } & \multicolumn{3}{|c|}{ CR@AliShan (mm) } & & \multicolumn{3}{|c|}{ CR@Yushan (mm) } \\
\hline & & Period A & Period B & B/A (\%) & & Period A & Period B & B/A (\%) \\
\hline 2004 & Mindulle & 1763.0 & 1678.0 & 95.2 & & 1014.1 & 859.4 & 84.7 \\
\hline 2005 & Haitang & 1291.5 & 992.0 & 76.8 & & 1187.5 & 775.5 & 65.3 \\
\hline 2006 & Bilis & 848.0 & 699.0 & 82.4 & & 623.8 & 435.2 & 69.8 \\
\hline 2008 & Kalmaegi & 703.0 & 219.5 & 31.2 & & 461.0 & 90.0 & 19.5 \\
\hline 2008 & Fungwong & 645.9 & 507.5 & 78.6 & & 437.0 & 230.0 & 52.6 \\
\hline 2009 & Morakot & 3135.5 & 2174.0 & 69.3 & & 2170.2 & 1266.5 & 58.4 \\
\hline
\end{tabular}

Note: Categ.: Category; CR: Cumulative rainfall; Period A: the whole analyzed time; Period B: from leaving land to the end of analyzed time. 
$3136 \mathrm{~mm}$ at ALiShan and $2170 \mathrm{~mm}$ at YuShan in Typhoon Morakot. The ratio of periods B to A illustrates the dominance of heavy rainfall even after the center of the typhoon left Taiwan. With the exception of Typhoon Kalmaegi, all other typhoons are with heavier rainfall in the post-landfall period. Figure 4 shows the moisture and wind velocity of the six typhoon cases averaged over the period A. Typhoons Bilis and Morakot are with very strong SW flow of approximately $15 \mathrm{~m} \mathrm{~s}^{-1}$ and with higher specific humidity of $0.019 \mathrm{~kg} \mathrm{~kg}^{-1}$. Other typhoons are with a typical $10 \mathrm{~m} \mathrm{~s}^{-1}$ flow and $0.015 \mathrm{~kg} \mathrm{~kg}^{-1}$ humidity.

\section{THE ANNSME RESULTS}

The time series of rainfall observations and the TRCM rainfall predictions are shown in Fig. 5 for ALiShan and YuShan stations. The differences between observed and predicted rainfalls (DIFF) are also indicated. The DIFFs (a)

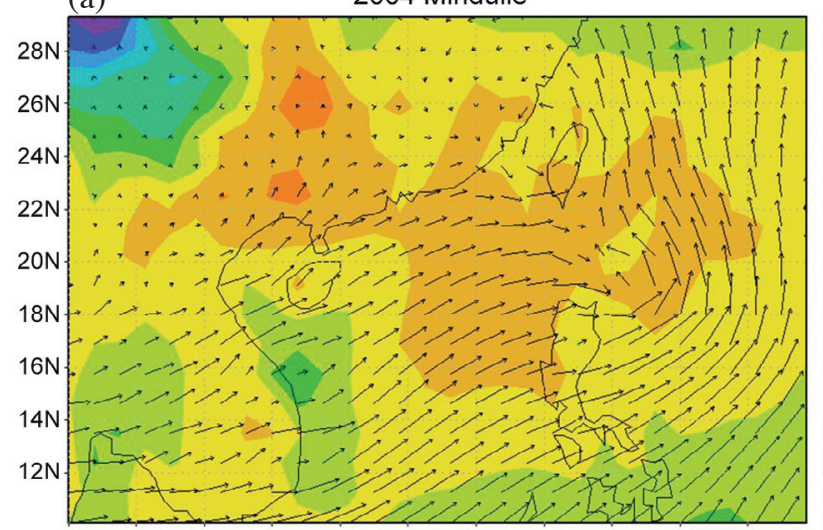

(c)

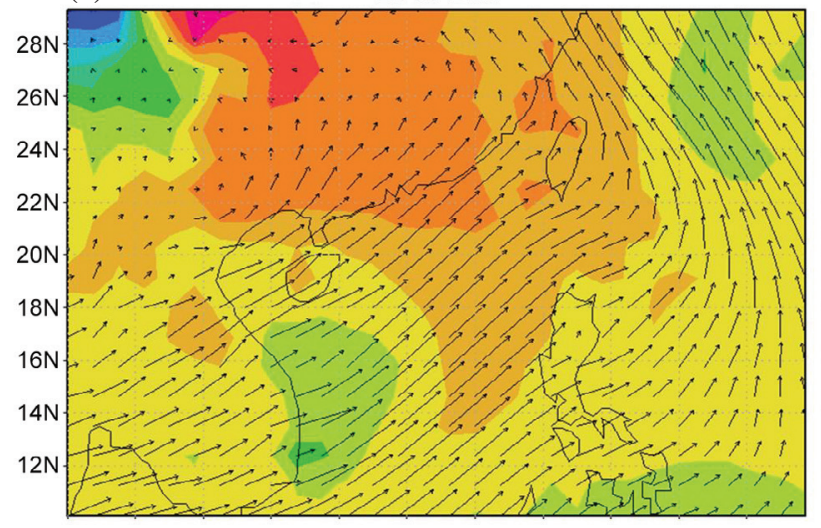

(e)

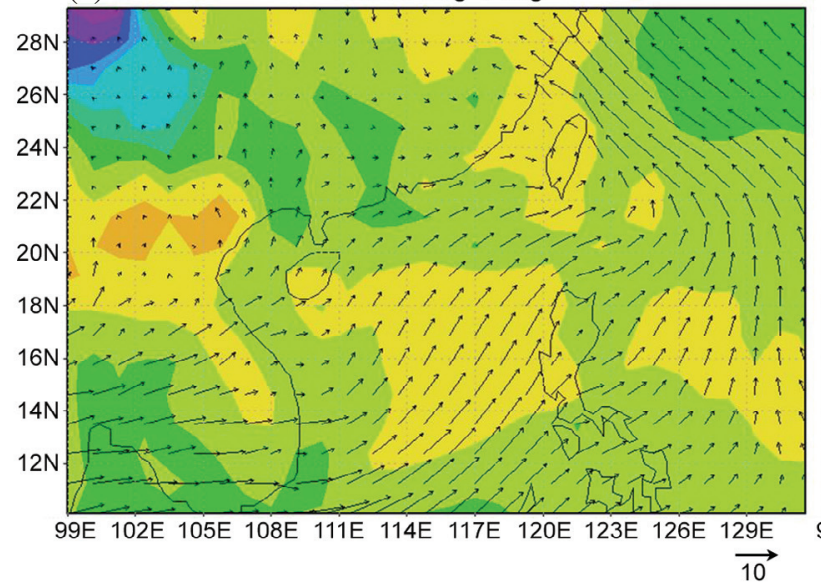

(b)

2005 Haitang

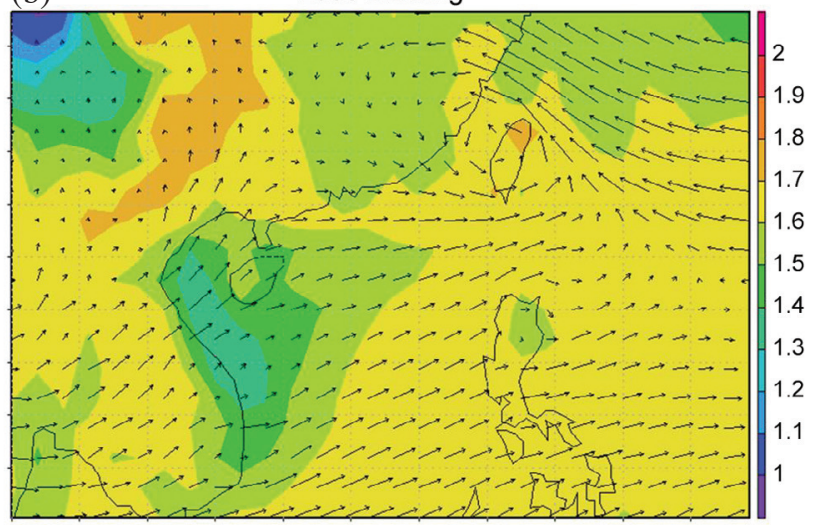

(d)

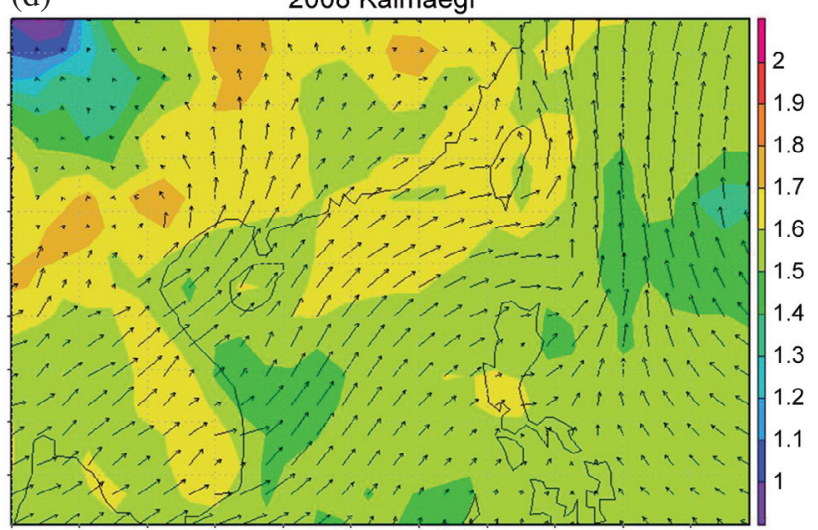

(f)

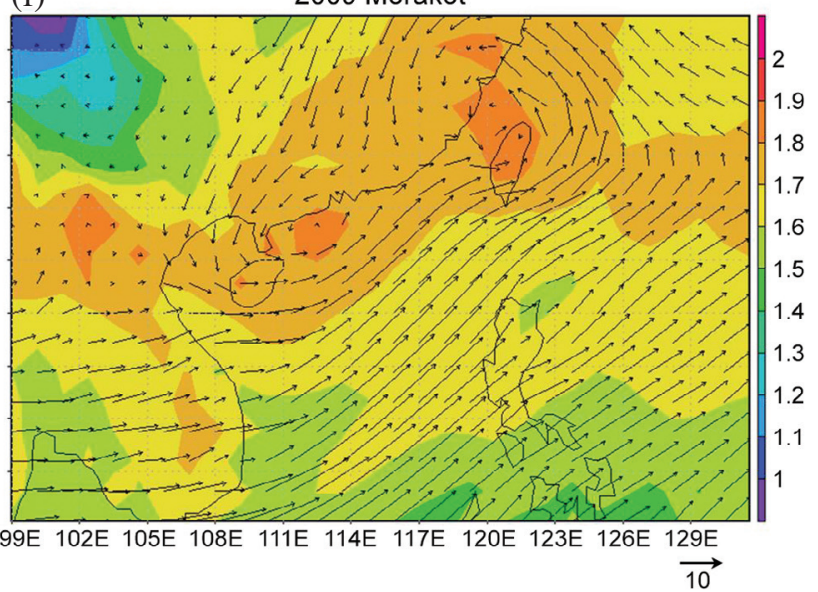

Fig. 4. The averages of $925 \mathrm{hPa}$ wind speed vectors $\left(\mathrm{m} \mathrm{s}^{-1}\right)$ and specific humidity $\left(10^{-2} \mathrm{~kg} \mathrm{~kg}^{-1}\right)$ (shaded) of the six selected typhoons: (a) Mindulle, (b) Haitang, (c) Bilis, (d) Kalmaegi, (e) Fungwong, and (f) Morakot. 
(a)

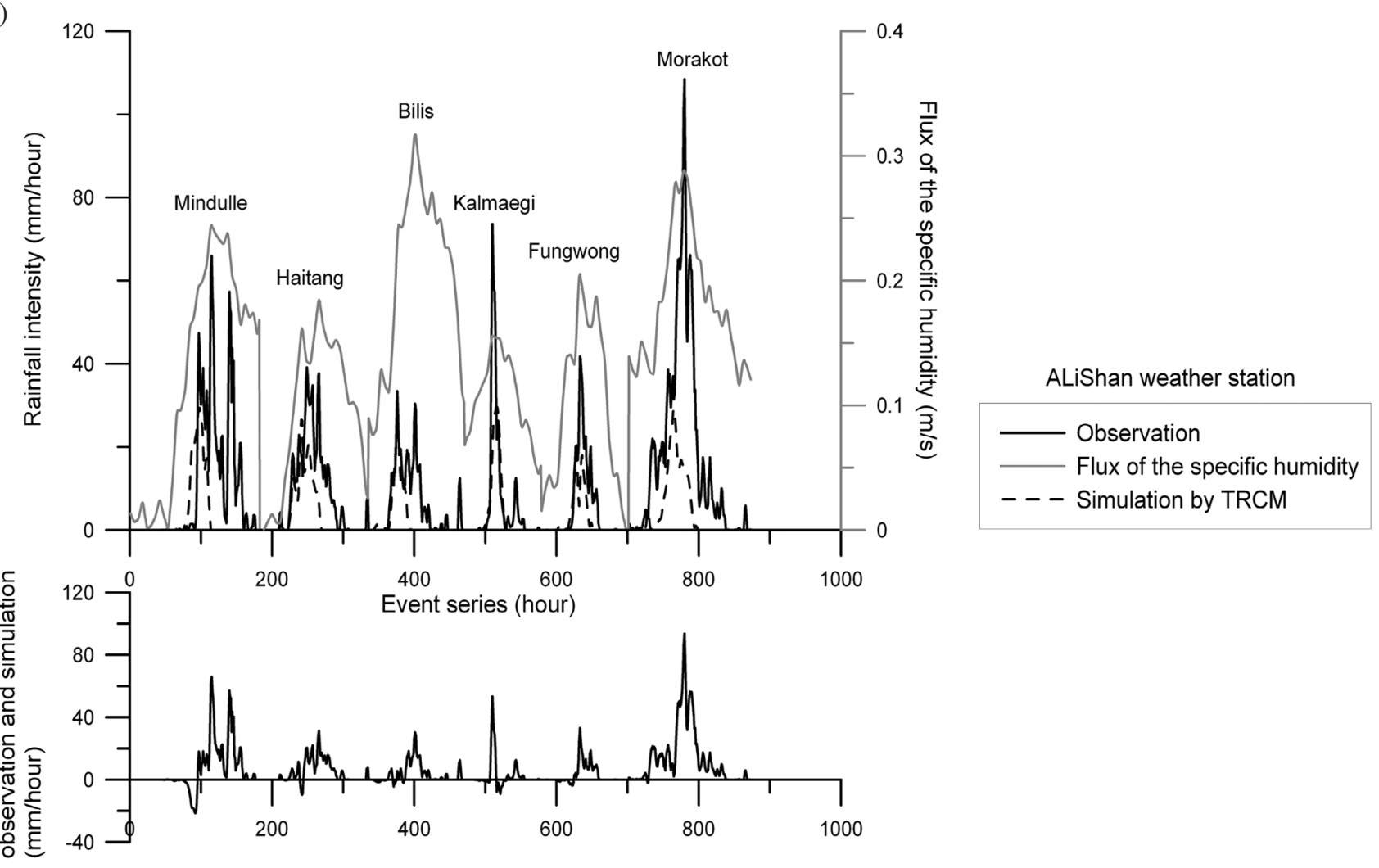

(b)
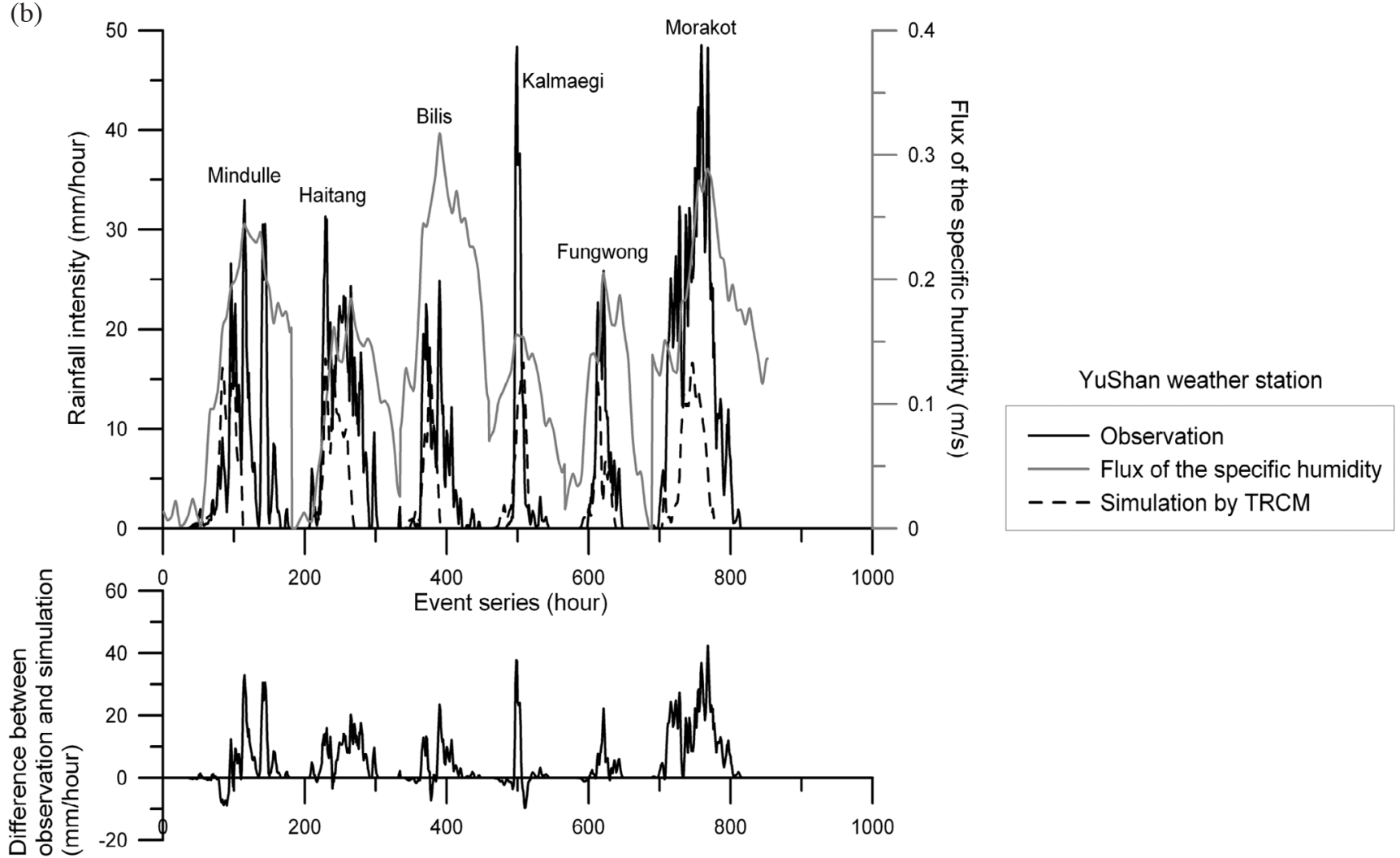

Fig. 5. The time series of averages of moisture flux of the SW monsoon in detecting zone $\left(\mathrm{m} \mathrm{s}^{-1}\right)$, the observed and simulated rainfall intensities via the TRCM, and their difference at (a) ALiShan and (b) YuShan weather stations $\left(\mathrm{mm} \mathrm{h}^{-1}\right)$ for the six selected typhoons. 
are mostly positive indicating an underestimation of predictions. Moreover, there are peaks local in times which are not produced by the TRCM. For extreme rainfall events such as Typhoon Morakot and ones in Table 2, factors such as a SW monsoon water vapor supply may not be properly represented in the typhoon climatology, as most of the typhoons are not necessarily associated with a strong SW monsoon flow. Table 3 gives the time difference between the peak of rainfall and the peak SW moisture flux for the six typhoons. It appears that there is no general relationship for the time differences, only Typhoons Morakot and Mindulle show the peak rainfall after the peak SW water vapor flux. It is possible that the maximum rainfalls in the up-streams of the two stations are not only affected by the intensity of the SW monsoon, but also affected by the mesoscale convections. The peak rainfall results when a sufficient moisture supply exists. With this in mind, we want to establish a threshold for the SW moisture for heavy rain predictions. We define the effective moisture flux as the flux above the threshold.

Figure 6 is the scatter plots of the DIFF data and moisture flux in ALiShan and YuShan, respectively. Figure 6 illustrates not only an increasing trend of extreme rainfall towards the moisture flux, but also a growing variance with the moisture flux. To identify the threshold of the effective moisture flux, each 30-data set of moisture flux are averaged with increasing rainfall intensity, and a transition point is carried out based on the maximum slop difference of two linear regressions for two segments (Brunder et al. 1981). The threshold of effective moisture flux at ALiShan and YuShan stations for all test cases are shown in Table 4. The moisture flux threshold variability in ALiShan (from 0.1527 to $0.1863 \mathrm{~m} \mathrm{~s}^{-1}$ ) is smaller than that of YuShan (from 0.1363 to $0.2137 \mathrm{~m} \mathrm{~s}^{-1}$ ). The ALiShan station is with a more robust threshold. The lower threshold of ALiShan than that of YuShan suggests that the extreme rainfall enhanced by the SW monsoon flow is easier to implement in ALiShan

Table 3. The time difference between the peak of moisture flux and the peak of DIFF at ALiShan and YuShan weather stations.

\begin{tabular}{lcccccc}
\hline & Mindulle & Haitang & Bilis & Kalmaegi & Fungwong & Morakot \\
\hline ALiShan & -1 & 6 & 0 & 3 & 12 & -11 \\
YuShan & -2 & 6 & 10 & 4 & 12 & -20 \\
\hline
\end{tabular}
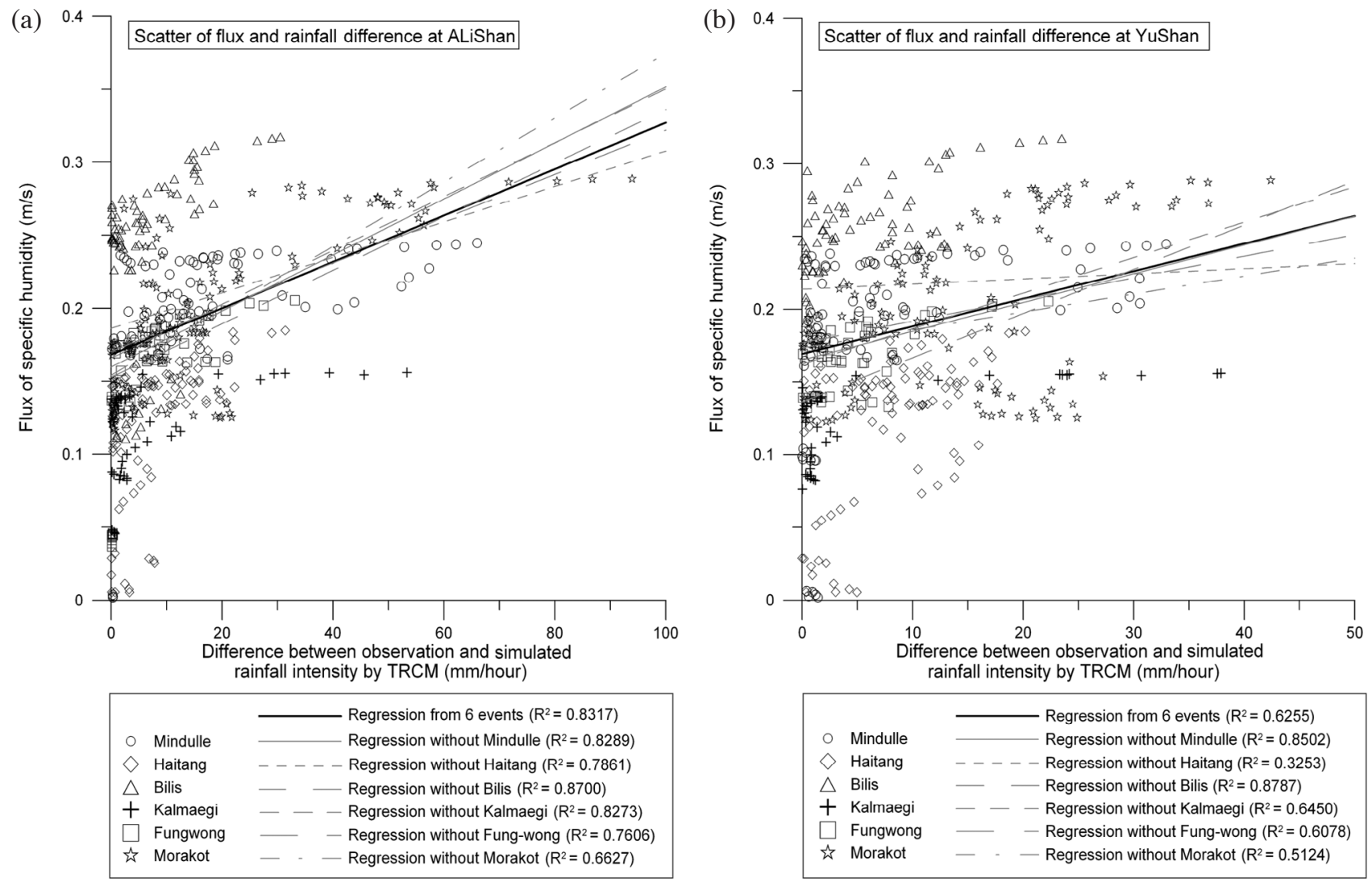

Fig. 6. Scatter plot of the DIFF and the SW monsoon moisture flux at (a) ALiShan and (b) YuShan weather stations. 
station. This is consistent with the fact that the altitude of ALiShan is lower than YuShan.

Figure 7 gives the linear regressions of DIFF and the effective moisture flux over the stations. From the linear regression formula, a FNN is adopted to estimate the residuals of DIFF to the linear regressions. Namely, the averages of western wind speed, southern wind speed, specific humidity, and the moisture flux in the SW moisture detecting zone are selected as the inputs of the FNN, and the residuals is the designed output.

The input-output data are separated into 3 groups for model construction: $4 / 5$ data as a training set, $1 / 10$ data as a validation set and $1 / 10$ data as a test set. Based on the threshold of effective moisture flux, 0.1683 and $0.1696 \mathrm{~m} \mathrm{~s}^{-1}$ at ALiShan and YuShan weather stations, respectively, there are 302 and 298 available data passing the thresholds from 874 and 853 observations in 6 typhoon events. Typhoon Kalmaegi is with 74 and $48 \mathrm{~mm} \mathrm{~h}^{-1}$ rainfall intensity in ALiShan and YuShan stations, respectively. Even if a significant SW monsoon was observed in Kalmaegi case, the maximum moisture flux of Kalmaegi is less than the thresholds of both stations. Thus, typhoons other than Kalmaegi contribute greatly in ANNSME. A trial and error method is applied to identify the optimum number of neurons in the hidden layer from 1 to 50. Consequently, the structures of the ANNSMEs at ALiShan and YuShan are 4-12-1 and 4-11-1 FNNs, respectively.

Figure 8 shows the performance of ANNSME to adjust the TRCM rainfall prediction. Based on the contribution of the SW monsoon, the TRCM rainfall prediction is modified through ANNSME in two steps: a linear transformation from the effective moisture of the SW monsoon to expect extra rainfall, and a FNN for estimating residual to the expected extra rainfall. The diagonal lines in the Fig. 8 suggest that the ANNSME provides a satisfied modified rainfall based on the information of the SW monsoon for the ALiShan and YuShan stations.

To demonstrate the value of our approach, we now test the performance of TRCM rainfall prediction with ANNSME model for Typhoons Mindulle and Morakot. For each of the test typhoon cases, we use the ANNSME model without the test typhoon case in the training data base. The results of Typhoons Mindulle and Morakot are illustrated in Figs. 9 and 10. The black dashed line is the TRCM

Table 4. The cross test for the threshold of effective moisture flux.

\begin{tabular}{cccccccc}
\hline \multirow{2}{*}{$\begin{array}{c}\text { Weather } \\
\text { station }\end{array}$} & \multicolumn{5}{c}{ Threshold of effective moisture flux $\left(\mathbf{m ~ s}^{-1}\right)$} \\
\cline { 2 - 8 } & $\mathbf{6}$ events & Mindulle & Haitang & Bilis & Kalmaegi & Fungwong & Morakot \\
\cline { 2 - 8 } & & 0.1597 & 0.1863 & 0.1527 & 0.1658 & 0.1705 & 0.1541 \\
ALiShan & 0.1683 & 0.1651 & 0.2137 & 0.1363 & 0.1622 & 0.1769 & 0.1734 \\
YuShan & 0.1693 & & &
\end{tabular}
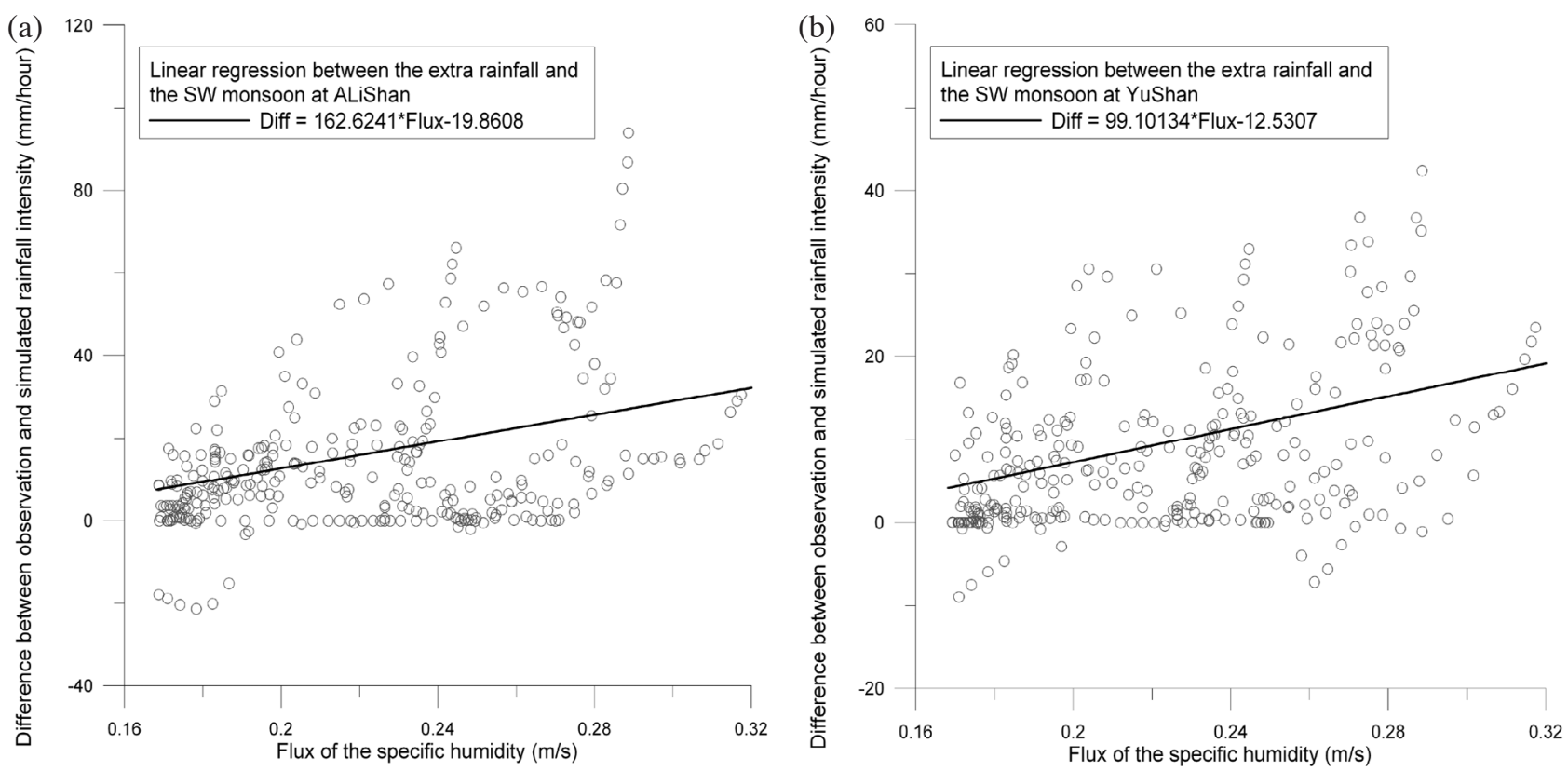

Fig. 7. Scatter plot of the DIFF and the moisture flux, and its linear regression at (a) ALiShan and (b) YuShan weather stations. 

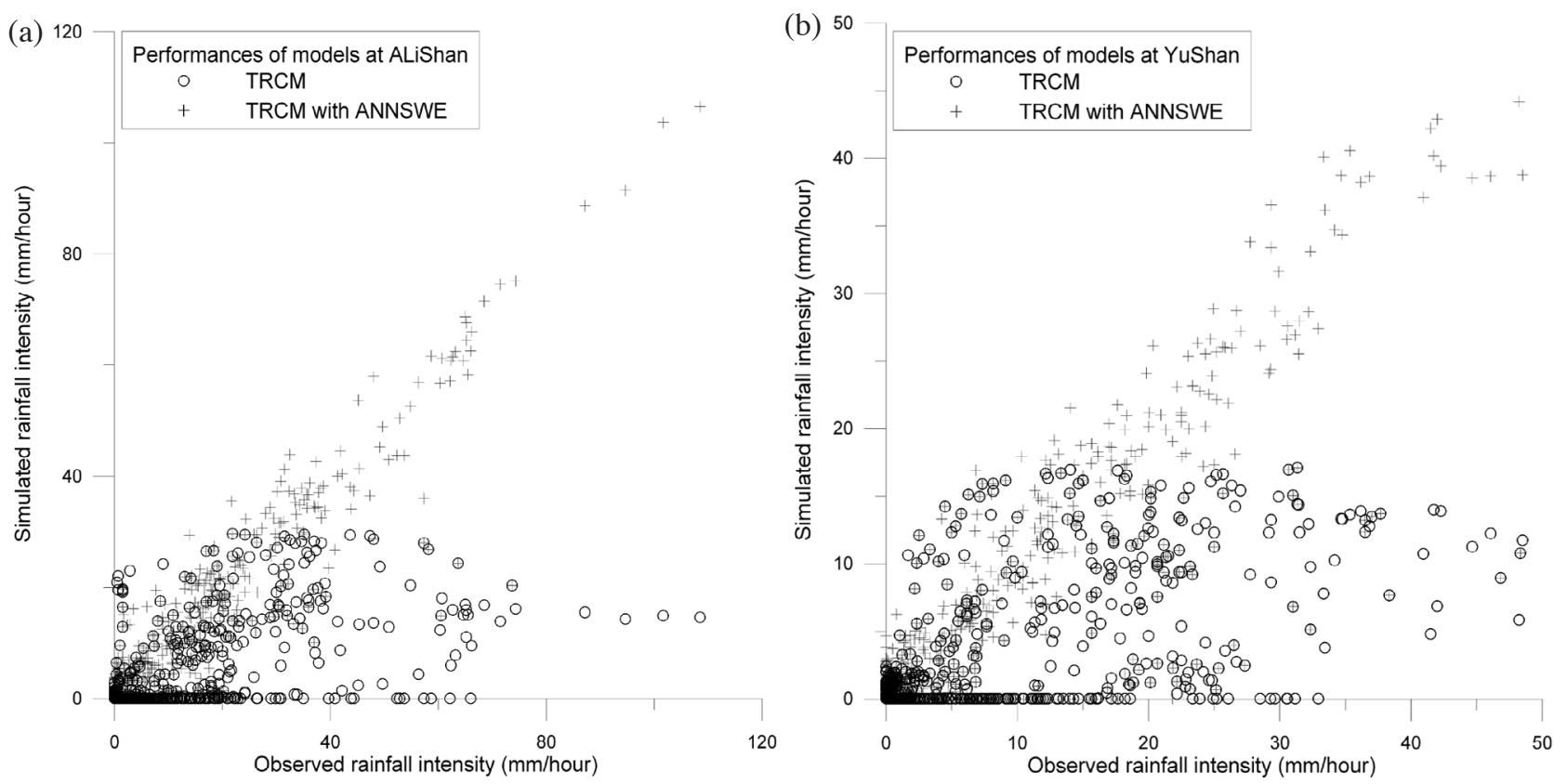

Fig. 8. The performance of the TRCM and the TRCM with ANNSME to observed rainfall intensity at (a) ALiShan and (b) YuShan weather stations.

(a)

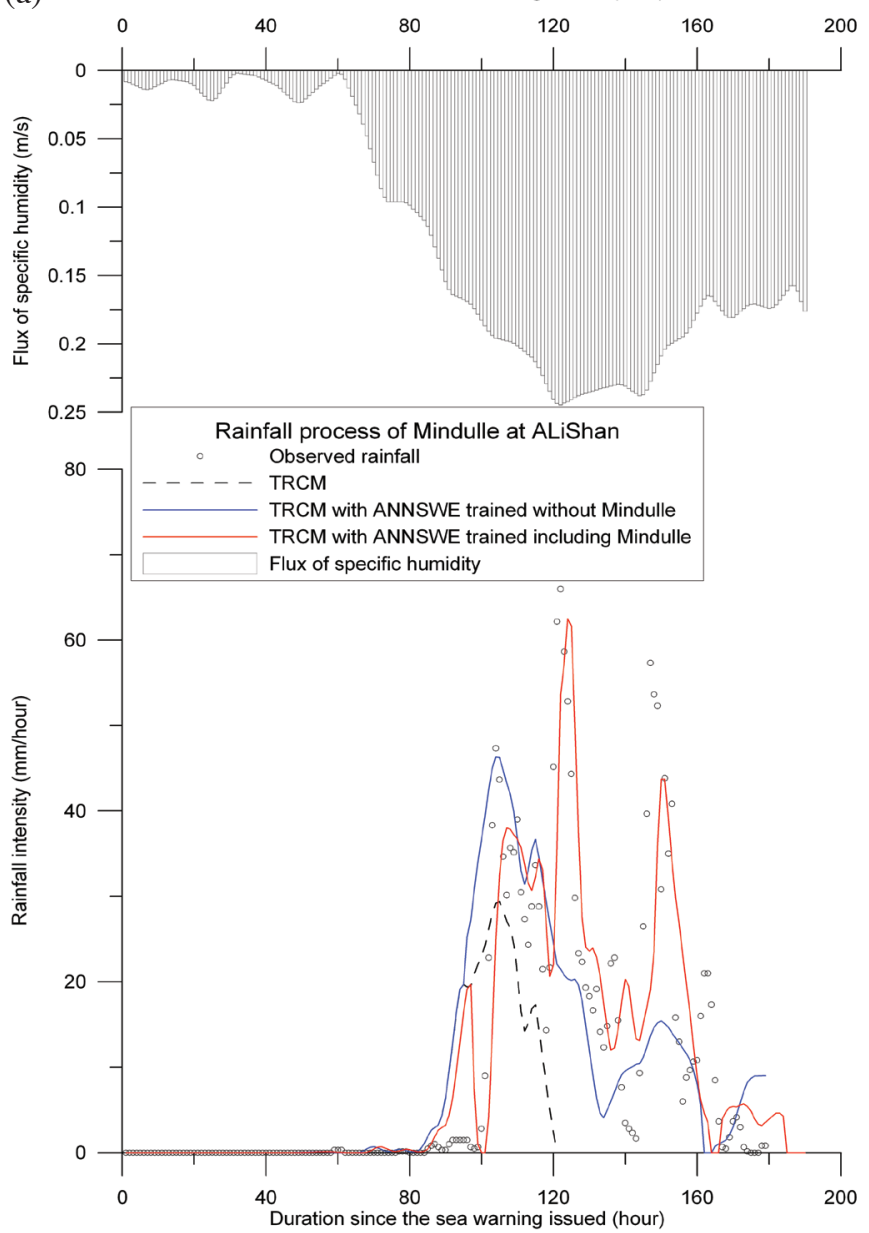

(b)

b) Duration since the sea warning issued (hour)

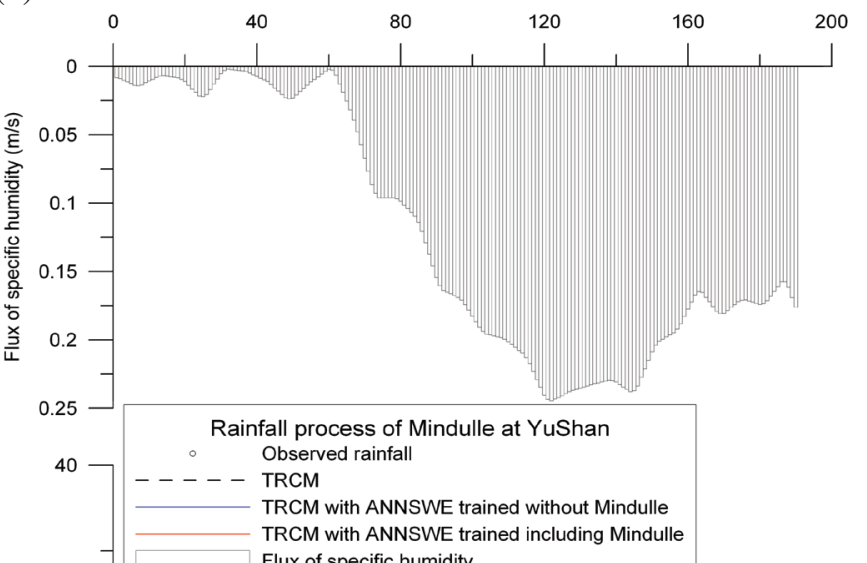

Fig. 9. The rainfall processes of typhoon Mindulle illustrated by observed rainfall (dot), the TRCM (black dash), the TRCM with ANNSME trained without Mindulle (blue), and the TRCM with ANNSME trained including Mindulle (red) at (a) ALiShan and (b) YuShan weather stations. 
prediction, the red line is ANNSME model with all cases in the data base and the blue line is the ANNSME model without the test case. The amount of the water vapor flux is also shown in the figures. It is not surprising that the ANNSME model with the test case in the data base results in a prediction so close to the observation. On the other hand, when the test case is removed from the training set, the prediction is still better than the original TRCM prediction, in that the amount of rainfall as well as the multiple peak of rainfall is predicted. The performances of original TRCM prediction and TRCM prediction with ANNSME are further evaluated by root mean square error (RMSE), error of cumulative rainfall (ECR), and error of the time for peak to arrive $\left(\mathrm{ET}_{\mathrm{p}}\right)$ in Table 5 (Pan et al. 2011). We found that the RMSE and ECR are improved through TRCM prediction with ANNSME in all cases except the extreme rainfall case at ALiShan in Typhoon Morakot. In such a case, the rainfall may be overestimated due to the fact that ANNs
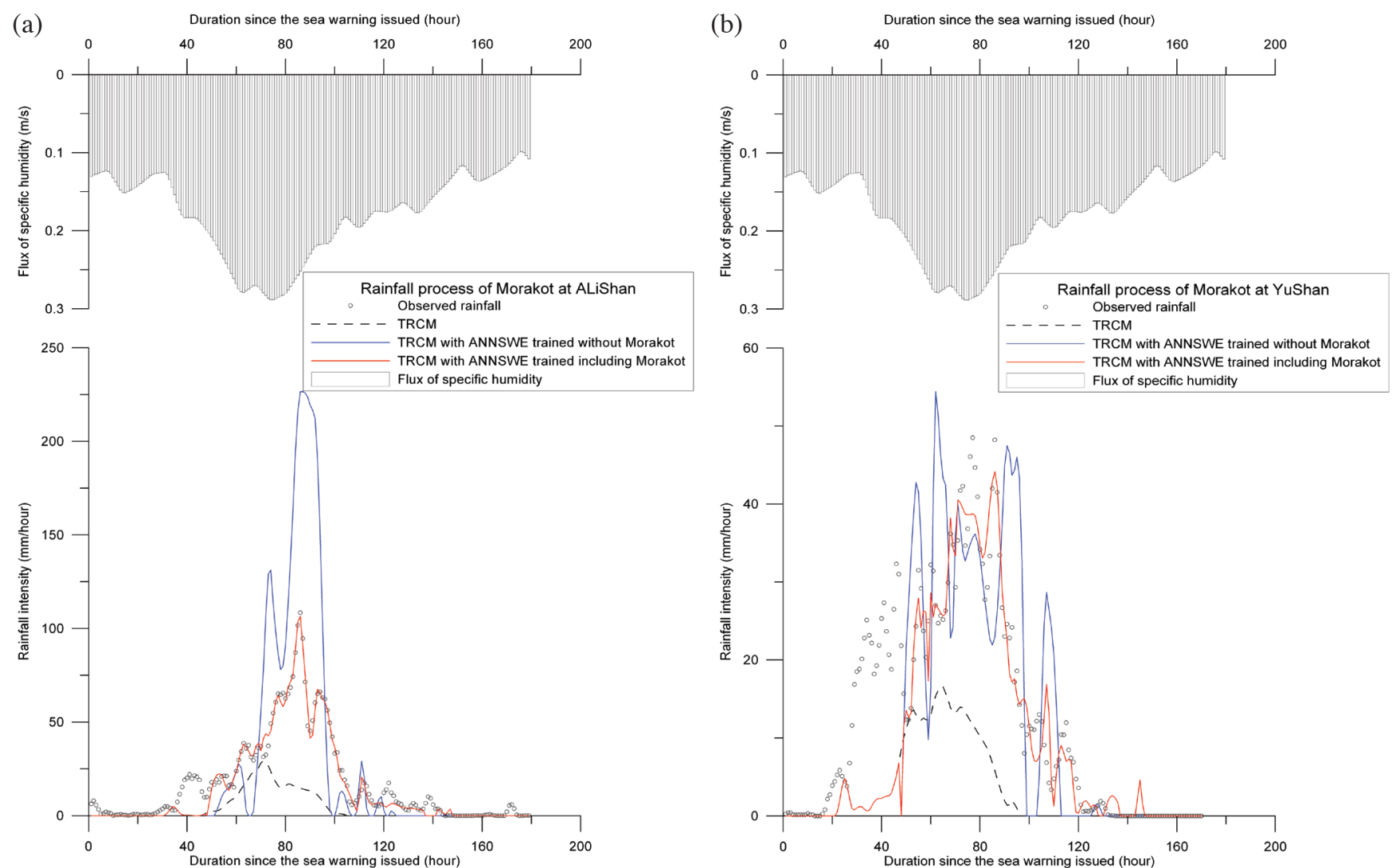

Fig. 10. The rainfall processes of typhoon Morakot illustrated by observed rainfall (dot), the TRCM (black dash), the TRCM with ANNSME trained without Morakot (blue), and the TRCM with ANNSME trained including Morakot (red) at (a) ALiShan and (b) YuShan weather stations.

Table 5. The performance of TRCM and ANNSME evaluated by root mean square error (RMSE), error of cumulative rainfall (ECR), and error of the time for peak to arrive $\left(\mathrm{ET}_{\mathrm{p}}\right)$.

\begin{tabular}{|c|c|c|c|c|c|}
\hline Typhoon & Weather station & Model & 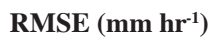 & $\operatorname{ECR}(\%)$ & $\operatorname{ET}_{P}(\mathbf{h r})$ \\
\hline \multirow{4}{*}{ Mindulle } & \multirow{2}{*}{ YuShan } & TRCM & 12.5 & -72.3 & -16.0 \\
\hline & & TRCM+ANN & 9.2 & 11.4 & -14.0 \\
\hline & \multirow{2}{*}{ ALiShan } & TRCM & 23.4 & -71.0 & -17.0 \\
\hline & & TRCM+ANN & 16.8 & -10.5 & -18.0 \\
\hline \multirow{4}{*}{ Morakot } & \multirow{2}{*}{ YuShan } & TRCM & 16.1 & -69.9 & -13.0 \\
\hline & & TRCM+ANN & 12.8 & 11.6 & -15.0 \\
\hline & \multirow{2}{*}{ ALiShan } & TRCM & 30.6 & -75.0 & -15.0 \\
\hline & & TRCM+ANN & 54.0 & 56.3 & 1.0 \\
\hline
\end{tabular}

Note: TRCM+ANN means TRCM prediction with ANNSME. 
are not effective for extrapolation (Yin et al. 2003). On the other hand, the $\mathrm{ET}_{\mathrm{p}}$ is improved significantly for the single peak event, like the test case at ALiShan in Typhoon Morakot. Even with very limited training cases, Table 5, Figs. 9 and 10 indicate the ANNSME is robust and suitable for improvement of quantitative rainfall prediction.

\section{CONCLUSION}

This study proposes an ANN-based SW monsoon enhancement to improve the typhoon rainfall forecast over the mountain. The ALiShan and YuShan's rainfall data and the SW monsoon moisture flux are used in the algorithm. The strength of the SW monsoon is evaluated in terms of the moisture flux in the detecting zone located at sea over southwestern Taiwan. The analysis suggests that the moisture flux during the landfall periods of Typhoon Mindulle, Bilis, Fungwong and Morakot were accompanied a with large scale monsoon flow transporting water vapor and that of Typhoons Kalmaegi and Haitaing were with only local southwester wind. A linear regression is adopted to identify the threshold of the moisture flux for effective moisture flux to mountainous rainfall in the southwestern Taiwan. A FNN is then applied to estimate the residual from linear model to the difference between simulated rainfall by the TRCM and observations. Our main results are in Figs. 8 10 , which suggest that ANNSME is robust and the better predictions of both total rainfall and multiple rainfall peaks on the mountain. In the future, we would like to extend the study with more stations and also consider the cases with northeast monsoon enhancement.

Acknowledgements This research was supported by Taiwan's National Research Council through grants NSC962111-M-002-002, NSC97-2628-M-002-023，97R0066-69 and MOTC-CWB-96-2M-01 to National Taiwan University. We thank the Center for Weather Climate and Disaster Research at National Taiwan University and Taida Institute for Mathematical Sciences for the additional support.

\section{REFERENCES}

Bellerby, T., M. Todd, D. Kniveton, and C. Kidd, 2000: Rainfall estimation from a combination of TRMM precipitation radar and GOES multispectral satellite imagery through the use of an artificial neural network. $J$. Appl. Meteorol., 39, 2115-2128, doi: 10.1175/1520-04 50(2001)040<2115:REFACO >2.0.CO;2. [Link]

Brunder, D. G., R. T. Coughlin, and E. J. McGroarty, 1981: A program for transition point analysis of experimental data. Comput.Biol. Med., 11, 9-15, doi: 10.1016/00104825(81)90011-1. [Link]

Chang, C. P., T.C. Yeh, and J. M. Chen, 1993: Effects of terrain on the surface structure of typhoons over Taiwan.
Mon. Weather Rev., 121, 734-752, doi: 10.1175/15200493(1993)121<0734:EOTOTS>2.0.CO;2. [Link]

Chen, S. T., C. C. Wu, W. J. Chen, and J. C. Hu, 2008: Rain-area identification using TRMM/TMI data by data mining approach. J. Adv. Comput. Intell. Inf., 12, 243-248.

Chien, F. C. and H. C. Kuo, 2011: On the extreme rainfall of Typhoon Morakot (2009). J. Geophys. Res., 116, D05104, doi: 10.1029/2010JD015092. [Link]

Chien, F. C., Y. C. Liu, and C. S. Lee, 2008: Heavy rainfall and southwesterly flow after the leaving of Typhoon Mindulle (2004) from Taiwan. J. Meteorol. Soc. Jpn., 86, 17-41, doi: 10.2151/jmsj.86.17. [Link]

French, M.N., W.F. Krajewski, and R.R. Cuykendall, 1992: Rainfall forecasting in space and time using a neural network. J. Hydrol., 137, 1-31, doi: 10.1016/0022-16 94(92)90046-X. [Link]

Gardner, M. W. and S. R. Dorling, 1998: Artificial neural networks (the multilayer perceptron) - A review of applications in the atmospheric sciences. Atmos. Environ., 32, 2627-2636, doi: 10.1016/S1352-2310(97)00447-0. [Link]

Ge, X., T. Li, S. Zhang, and M. Peng, 2010: What causes the extremely heavy rainfall in Taiwan during Typhoon Morakot (2009)? Atmos. Sci. Lett., 11, 45-50, doi: 10.1002/asl.255. [Link]

Hong, C. C., M. Y. Lee, H. H. Hsu, and J. L. Kuo, 2010: Role of submonthly disturbance and 40-50 day ISO on the extreme rainfall event associated with Typhoon Morakot (2009) in Southern Taiwan. Geophys. Res. Lett., 37, L08805, doi: 10.1029/2010GL042761. [Link]

Hong, Y., K. L. Hsu, S. Sorooshian, and X. Gao, 2004: Precipitation estimation from remotely sensed imagery using an artificial neural network cloud classification system. J. Appl. Meteorol., 43, 1834-1853, doi: 10.11 75/JAM2173.1. [Link]

Hsu, K. L., X. Gao, S. Sorooshian, and H. V. Gupta, 1997: Precipitation estimation from remotely sensed information using artificial neural networks. J. Appl. Meteorol., 36, 1176-1190, doi: 10.1175/1520-0450(1997) 036<1176:PEFRSI > 2.0.CO;2. [Link]

Lee, C. S., L. R. Huang, H. S. Shen, and S. T. Wang, 2006: A climatology model for forecasting typhoon rainfall in Taiwan. Nat. Hazards, 37, 87-105, doi: 10.1007/ s11069-005-4658-8. [Link]

Lee, C. S., Y. C. Liu, and F. C. Chien, 2008: The secondary low and heavy rainfall associated with Typhoon Mindulle (2004). Mon. Weather Rev., 136, 1260-1283, doi: 10.1175/2007MWR2069.1. [Link]

Lin, C. Y., H. M. Hsu, Y. F. Sheng, C. H. Kuo, and Y. A. Liou, 2010: Mesoscale processes for super heavy rainfall of Typhoon Morakot (2009) over Southern Taiwan. Atmos. Chem. Phys. Discuss., 10, 13495-13517, doi: 10.5194/acpd-10-13495-2010. [Link] 
Lin, G. F. and L. H. Chen, 2005: Application of an artificial neural network to typhoon rainfall forecasting. $H y$ drol. Process., 19, 1825-1837, doi: 10.1002/hyp.5638. [Link]

Lin, G. F., G. R. Chen, M. C. Wu, and Y. C. Chou, 2009: Effective forecasting of hourly typhoon rainfall using support vector machines. Water Resour. Res., 45, W08440, doi: 10.1029/2009WR007911. [Link]

Olsson, J., C. B. Uvo, K. Jinno, A. Kawamura, K. Nishiyama, N. Koreeda, T. Nakashima, and O. Morita, 2004: Neural networks for rainfall forecasting by atmospheric downscaling. J. Hydrol. Eng., 9, 1-12, doi: 10.1061/ (ASCE) 1084-0699(2004)9:1(1). [Link]

Pan, T. Y., R. Y. Wang, and J. S. Lai, 2007: A deterministic linearized recurrent neural network for recognizing the transition of rainfall-runoff processes. Adv. Water Resour., 30, 1797-1814, doi: 10.1016/j.advwatres.20 07.02.009. [Link]

Pan, T. Y., J. S. Lai, T. J. Chang, H. K. Chang, K. C. Chang, and Y.C. Tan, 2011: Hybrid neural networks in rainfall-inundation forecasting based on a synthetic potential inundation database. Nat. Hazards Earth Syst. Sci., 11, 771-787, doi: 10.5194/nhess-11-771-2011. [Link]

Scales, L. E., 1985: Introduction to Nonlinear Optimization.
Springer-Verlag, New York, 243 pp.

Tsai, M. S., J. L. Wang, J. P. Hou, and T. H. He, 2010: The simulation of heavy rainfall in Peng-Hu associated with Typhoon Kalmaegi (2008). Jt. 2010 CWB Weather Anal. and Forecast. and COAA $5^{\text {th }}$ Int. OceanAtmos. Conf., June 28-30, 2010 Central Weather Bureau, Taipei. (in Chinese)

Tsoi, A. C. and A. Back, 1997: Discrete time recurrent neural network architectures: A unifying review. Neurocomputing, 15, 183-223. doi: 10.1016/S0925-2312(97) 00161-6. [Link]

Wang, S. T., 1992: An integrated study of the impact of the orography in Taiwan on the movement, intensity, structure, wind and rainfall distribution of invading typhoons. Research report No. 80-73, NSC 80-0414P052-02B, Taiwan, 285 pp. (in Chinese)

Wu, C. C., K. K. W. Cheung, and Y. Y. Lo, 2009: Numerical study of the rainfall event due to the interaction of Typhoon Babs (1998) and the Northeasterly monsoon. Mon. Weather Rev., 137, 2049-2064, doi: 10.1175/2009MWR2757.1. [Link]

Yin, C., L. Rosendahl, and Z. Luo, 2003: Methods to improve prediction performance of ANN models. Simul. Model. Pract. Theory, 11, 211-222, doi: 10.1016/S15 69-190X(03)00044-3. [Link] 